\title{
Jurassic surgery and immunity enhancement by alkyglycerols of shark liver oil
}

Beniamino Palmieri ${ }^{1}$, Alfonso Pennelli ${ }^{2,4}$ and Alessandro Di Cerbo ${ }^{3,4^{*}}$

\begin{abstract}
Background: Shark liver oil (SLO) contains both alkylglycerols (AKG) and squalene and is an ancient remedy among the fishermen on the west coast of Norway and Sweden. Literature reports showed that alkyglycerols enhance Fc-receptor mediated phagocytosis, increase humoral immune response and delay hypersensitivity reactions.

Methods: On this background we performed an open spontaneous study on 40 very old aged surgical patients preoperatively treated with alkyglycerols (500 mg twice a day for 4 weeks), in order to reduce the risks of operation, counteracting the postoperative inflammatory and anergic conditions thus achieving quick and plain recovery. To better understand the possible therapeutic impact of alkyglycerols we compared on a case/control basis treated versus untreated patients submitted contemporarily to the identical operation and exposed to the same environmental and seasonal risks.
\end{abstract}

Results: The onset of complications was reduced in the alkyglycerols treated group and the compliance to the natural treatment was excellent without any serious adverse effect. WBC count and IgG significant increase (respectively $p<0.05$ and $p<0.001$ ) might explain some sort of protection against infectious agents and wound repair adverse events. Also lymphocytes concentration significantly increased in the AKG treated group $(p<0.001)$ whereas a slight decrease was observed in the control group. Conversely neutrophils significantly decreased in the AKG treated group $(p<0.001)$ meaning that patients have no more infections and have re-established their physiologic state. However a significant increase was observed in the control group ( $p<0.05)$. CRP significantly decreased in the group receiving AKG ( $p<0.05)$, thus evidencing a slight antiinflammtory effect of the product. Also ESR decreased from a baseline in the group receiving AKG.

Conclusions: In conclusion we suggest the opportunity to introduce this nutraceutical product in dosages of 500 mg twice a day to very old people before surgical treatment for an effective modulation of leukocytes and soluble immune reactivity according with the shark liver oil consumption trend in the northern Europe countries folk medicine. For this reason it might be advisable a wider study on a substantially bigger patients cohort focused on the complication rate prevention or control.

Keywords: Alkylglycerols, Nutraceutical product, Immune reactivity modulation

\section{Background}

Shark liver oil (SLO) contains both alkylglycerols (AKG) and squalene and is an ancient remedy among the fishermen along the west coast of Norway and Sweden. It has been successfully used for wound healing [1], inflammatory lung [1] and alimentary tract [2] diseases, lymphadenopathy [3], cancer [4] and dermatitis [5]. In 1922 Tsujimoto

\footnotetext{
* Correspondence: alessandro811@hotmail.it

${ }^{3}$ Poliambulatorio del Secondo Parere, viale Reiter 14, Modena 41125, Italy

${ }^{4}$ Scuola di Specializzazione in Biochimica Clinica, G. d'Annunzio University, Chieti-Pescara, Italy

Full list of author information is available at the end of the article
}

and Toyama found AKG in SLO [6] and Sir Robert Robinson, a Nobel laureate, first synthesized them in 1930 [7]. In the natural sources, they are always found esterified with fatty acids. Structurally they are alkyl ethers of glycerol (Figure 1).

Brohult and Holmberg [8], using the unsaponifiable portion of different bone marrow fats as well as preparations containing esters of AKG in child leukemia, observed a pro-differentiating effect on the white blood cells leading to AKG clinical administration in actinic leucopenia [9]. In the early 1950s Astrid Brohult began experimenting 


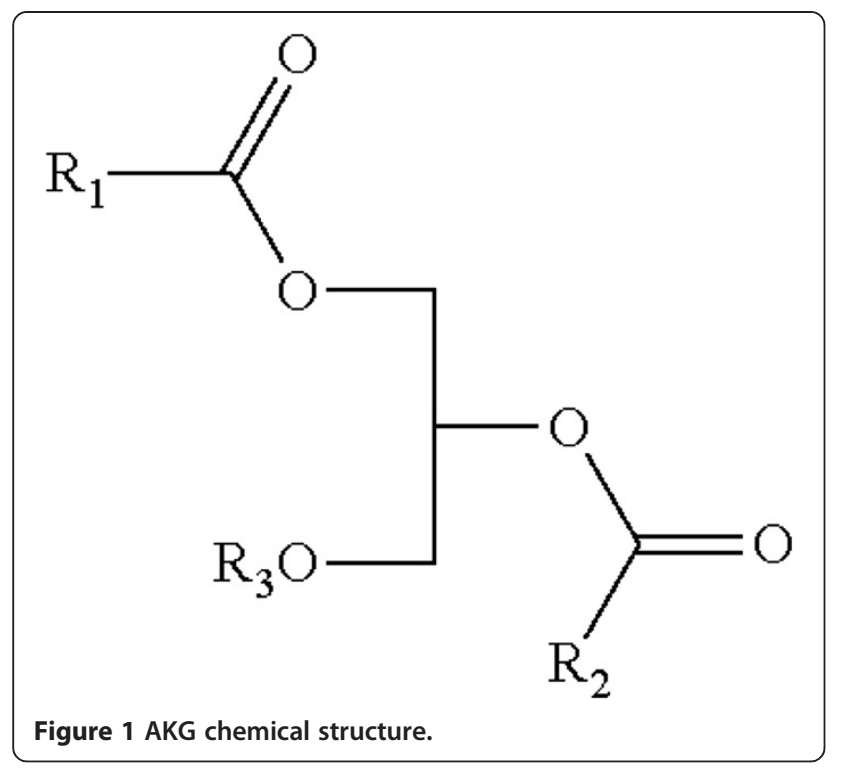

with AKG from the calf marrow on children with leukaemia, highlighting their property to stimulate white blood cells production and later, in 1963, she published a thesis on AKG and their use in uterine cancer irradiated patients demonstrating that AKG administration during radioactivity exposure reduced the bone marrow induced leukopenia following radiation therapy for uterine cervix carcinoma [10]. AKG treated patients showed a reduced complication rate and $47 \%$ fistula incidence reduction when AKG had been administered prior to radiation treatment $[11,12]$.

The principal AKG include chimyl (hexadecyl), batyl (octadecyl) and selachyl (octadecyl) ethers. Hallgreen et al. reported that glycerol ethers occur in the tissues in the form of diesters and alkyl acyl phosphatides [13]. 1O-Alkylglycerols and 1-O-(2-methoxyalkyl) glycerols were isolated from the neutral lipids and phospholipids of human colostrum, human milk, cow's milk, sheep's milk, human red bone marrow, red cells, blood plasma, and a uterine carcinoma (Table 1).

AKG and alkyl lysophospholipids significantly activate cytotoxic macrophages leading to enhanced Fc-receptor mediated phagocytosis and increase humoral immune response and delayed hypersensitivity reaction [14]. AKG have been shown to stimulate hematopoiesis, erythropoiesis, thrombocytosis and granulocytosis in experimental animals [15]. The anticancer effect of AKG might be due, according to the previously described studies, to the property of activating macrophages, and increasing the cytokines production such as Interleukine-12 (IL12) and Interferon-gamma (IFN- $\gamma$ ). Recruitment and activation of macrophages, in fact, is acknowledged to be fundamental in the primary antitumor defence [16]; while IFN- $\gamma$, (a T-cell derived lymphokine), inhibits a
Table 1 AKG percentage in human bone marrow, human milk and liver oil

\begin{tabular}{llll}
\hline Alkylglycerols & $\begin{array}{l}\text { Human bone } \\
\text { marrow }\end{array}$ & $\begin{array}{l}\text { Human } \\
\text { milk }\end{array}$ & $\begin{array}{l}\text { Greenland shark } \\
\text { liver oil }\end{array}$ \\
\hline $14: 0$ & & & 2.0 \\
$15^{\mathrm{a}}$ & & & 0.7 \\
$16: 0$ & 29.4 & 23.9 & 9.1 \\
$16: 1$ & & Trace & 10.8 \\
$17^{\mathrm{a}}$ & 7.6 & 3.6 & 3.6 \\
$18: 0$ & 24.6 & 22.8 & 2.8 \\
$18: 1$ & 16.7 & 33.8 & 59.4 \\
$18: 2$ & & 1.4 & 1.6 \\
$18: 3$ & & & \\
$19^{\mathrm{a}}$ & 6.1 & 2.4 & 1.5 \\
$20: 0$ & 2.9 & 1.6 & \\
$20: 1$ & 3.2 & 2.3 & 6.2 \\
$22: 0$ & 0.7 & 0.7 & \\
$22: 1$ & 5.1 & 3.4 & 2.2 \\
24 & & 2.1 & \\
\hline
\end{tabular}

The number of carbon atoms in the first column refers to the long-chain component of the molecule. The number after the column denotes the number of double bonds. ${ }^{a}$ Both branched and normal chains $C_{15}, C_{17}$, and $C_{19}$ are present [1].

wide number of malignant cells either directly counteracting cancer cells growth or through its immunomodulatory properties [17], IL-12 induces IFN- $\gamma$ secretion from naive and activated $\mathrm{T}$ and natural killer (NK) cells, enhances the cytotoxic activity of NK cells, cytotoxic T lymphocytes and lymphokine activated killer cells, increases of the proliferation of pre-activated $\mathrm{T}$ cells and NK cells, with a key role in the tumors defence [18-20]. On this basis, considering the potential benefits that AKG administration might have on very old pericentenarian patients submitted to surgery (we enclosed this ultra aged cohort of surgical candidates in the naive term of "Jurassic surgery"), we administered such compounds to 40 very old patients before surgical intervention in order to reduce the risks of operation and to achieve the best compliance and quick recovery.

We run an open spontaneous study on 40 operated cases comparing treated versus untreated patients undergone the same type of operation during the same historical period and the same environmental and seasonal risks.

\section{Results and discussion}

Results clearly indicate a significant increase of WBC concentration was observed in the AKG treated group, from a baseline value of $5071 \pm 236.4$ per $\mu$ l to $8309 \pm$ 
451.9 per $\mu \mathrm{l}(\mathrm{p}<0.05)$, compared with the control as enhanced physiological response to the surgical trauma and wound remodeling (Figure 2A).

Post operative immunoglobulins dosage of AKG treated patients revealed significant increase of both $\operatorname{IgM}$ (Figure 2E), from a baseline value of $54.95 \pm 2.26 \mathrm{mg} / \mathrm{dl}$ to $99.47 \pm 5.31 \mathrm{mg} / 100 \mathrm{ml}(\mathrm{p}<0.001$ ), and IgA (Figure $2 \mathrm{~F}$ ), from a baseline value of $66.4 \pm 3.62$ to $103.6 \pm 6.18 \mathrm{mg} / 100$ $\mathrm{ml}(\mathrm{p}<0.001)$, as a definite reaction against sorting infectious agents either in the sutured wound area or in the respiratory and urinary tract (IgA). As to IgG an overall increase was observed both in AKG treated group, from a baseline value of $718.9 \pm 27.34$ to $1008.6 \pm 52.69 \mathrm{mg} /$ $100 \mathrm{ml}$, meaning that the activation of plasma cells already primed for specific antibody response especially against infectious bacteria and fungi was occurred, and in the control group, from a baseline value of $822.2 \pm 63.98$ to $930.6 \pm 49.17 \mathrm{mg} / 100 \mathrm{ml}$. Also lymphocytes concentration significantly increased in the AKG treated group from a baseline value of $26.0 \pm 3.31 \times 10^{9} \mathrm{~L}$ to $30.50 \pm 1.13 \times$ $10^{9} \mathrm{~L}(\mathrm{p}<0.001)$; whereas a slight decrease, from a baseline value of $26.60 \pm 1.60 \times 10^{9} \mathrm{~L}$ to $23.30 \pm 1.61 \times 10^{9} \mathrm{~L}$, was observed in the control group (Figure $2 \mathrm{C}$ ). On the other hand neutrophils significantly decreased from a baseline value of $78.20 \pm 1.19 \mathrm{~mm}^{3}$ to $65.20 \pm 3.48 \mathrm{~mm}^{3}$ in the AKG treated group $(\mathrm{p}<0.001)$, meaning that patients have no more infections and have re-established their physiologic state. However a significant increase from a baseline value of $71.45 \pm 1.64 \mathrm{~mm}^{3}$ to $77.15 \pm 1.11 \mathrm{~mm}^{3}$ was observed in the control group ( $<<0.05)$ (Figure 2B).

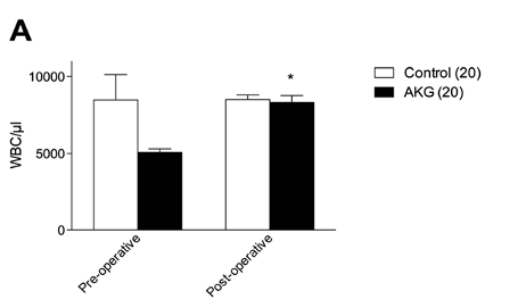

B

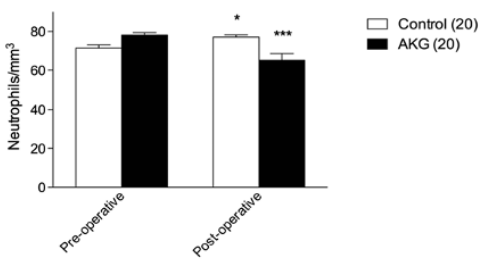

C

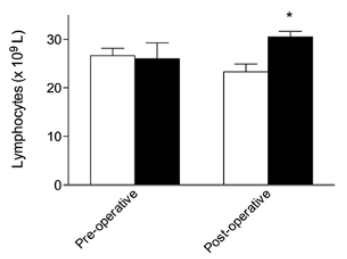

$\mathbf{E}$

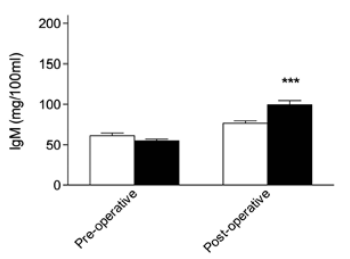

G

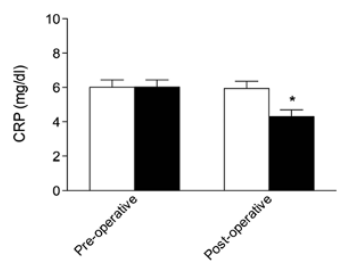

믈 Control (20)

D

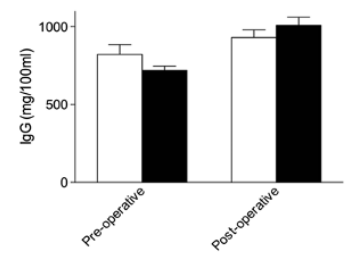

$\square$ Control (20)

$\mathbf{F}$
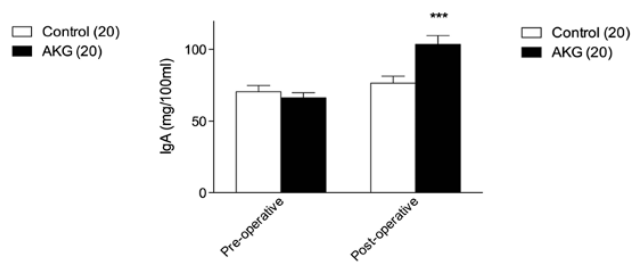

H
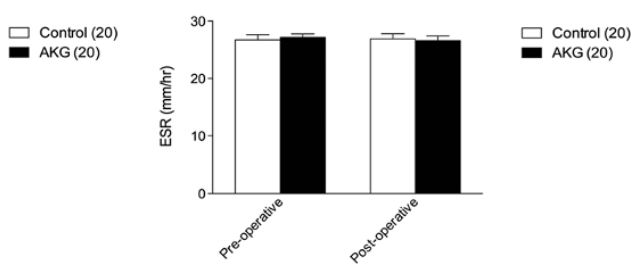

Figure 2 Measurements of biochemical parameters. A. Schematic representation of the improvement in leukocytes in the AKG treated group meaning a enhanced physiological response to the surgical trauma and wound remodeling; $\mathbf{B}$. Schematic representation of the decrease of neutrophils in the AKG treated group meaning the absence of infections and a re-established physiologic state; $\mathbf{C}$. Schematic representation of the increase of lymphocytes in the AKG treated group; D-F. Schematic representations of the improvement in IgG, IgM and IgA respectively in the AKG treated group, meaning an activation of plasma cells primed for specific antibody response and a definite reaction against sorting infectious agents, respectively; G. Schematic representation of the decrease of CRP in the AKG treated group meaning a slight antiinflammtory effect of the product; $\mathbf{H}$. Schematic representation of the decrease of ESR in the AKG treated group ${ }^{*} p<0.05,{ }^{* *} p<0.001$. 
CRP significantly decreased from a baseline value of $6.03 \pm 0.41 \mathrm{mg} / \mathrm{dl}$ to $4.31 \pm 0.38 \mathrm{mg} / \mathrm{dl}$ in the group receiving AKG ( $\mathrm{p}<0.05)$, thus evidencing a slight antiinflammtory effect of the product (Figure 2G). ESR decreased from a baseline value of $27.18 \pm 0.61 \mathrm{~mm} / \mathrm{hr}$ to $26.60 \pm 0.8$ $\mathrm{mm} / \mathrm{hr}$ in the group receiving AKG (Figure $2 \mathrm{H}$ ).

The onset of complications such as broncopneumonia, pleuritis, thromboembolism and wound disruption was reduced in the AKG treated group and the compliance to the natural treatment was excellent without any adverse effect; moreover WBC count restoration and IgG increase might at least partially explain some sort of protection against infectious agents and wound repair adverse events.

In the control group, along with previously cited complications we also observed fever episodes almost due to local and systemic low level of both non specific and specific defence of these very old patients.

Very old aged surgical patients are quite fragile and require great care in order to avoid both localized or systemic infections. Based on the folk medicine experience, we tried the administration of AKG in the perioperative phase in order to evaluate if its well reknown immunomodulating activity, even in the extreme life decade, might be useful to prevent either local or systemic surgical complications. Our patients reacted positively to AKG administration and the compliance of the molecule was very high with no drop out due to the optimal tolerance and safety.

Notwithstanding this small cohort of aged patients, the concordant hemato-immunological effects of AKG administration reduced both the number and the severity of complications in the treated patients and was shown to be helpful for a quick and easy recovery.

\section{Conclusions}

In conclusion we suggest the opportunity to introduce this nutraceutical product for an effective modulation of leukocytes and soluble immune reactivity according with the shark liver oil consumption trend in the northern Europe countries folk medicine. The shark liver oil, accordingly with the folk medicine tradition, administered in dosages of $500 \mathrm{mg}$ twice a day to very old people before surgical treatment induced a significant increase of WBC, lymphocytes, IgM and IgA in the postoperative period. The compound had not any kind of intolerance or side effects, and the treated patients had a plain uneventful outcome notwithstanding the fragile condition due to the extreme life decade. For this reason it might be advisable a wider study on a substantially bigger patients cohort focused on the complication rate prevention or control.

\section{Methods}

Forty patients (mean age \pm SEM, $97.20 \pm 0.86$ years; $57.5 \%$ males, $42.5 \%$ females) were admitted to surgical outpatient office for a preliminary evaluation of intervention feasibility.
They were affected by the following surgical diseases: umbilical hernia (2 cases), inguinal hernia (6 cases), lower leg varyces (4 cases), laparoscopic cholecystectomy (8 cases), breast cancer ( 2 cases), hydrocele (4 cases), phymosis (2 cases), skin cancer ( 2 spinocellular cancer, 2 basocellular cancer and 2 melanomas), laparocele (4 cases), giant lipoma (2 cases). Patients were equally distributed, in terms of affecting disease, in two groups, control (12 males and 8 females) and AKG (11 males and 9 females).

They were matched as case control along their recruitment period which lasted from January 2011 up to October 2013.

The preliminary selection of the patients to be treated was related to the finding of a low total WBC count, shift of the formula to neutrophilia (above 75\% neutrophils) and serum immunoglobulin level. In order to prevent post op infection on a standardized basis we used ceftriaxone 1 gr pre op followed by the same dosage daily i. $\mathrm{m}$. for the following 4 days. Antiinflammatory drugs were ruled out from the schedule and for the pain control we used only tramadol $100 \mathrm{mg}$ 2-3 times a day and Phentanil (Durogesic 25, 50, $100 \mathrm{mg}$ tailored on pain intensity), in order to avoid individual variations in biochemical parameters due to interfering molecules.

The investigated parameters, before and after 2 weeks of surgical intervention, were inflammation indexes (reactive $C$ protein or CRP, erythrocyte sedimentation rate or ESR), total leucocyte number and formula and serum immunoglobulins (IgA and IgM).

The AKG (Lysi Italy, Manzano (UD), Italy; $500 \mathrm{mg}$ of pure alkylglycerols per capsule) administration (500 mg twice a day) started at the first surgical admission visit and prolonged along 4 weeks, with temporary withdrawal from the morning of operation to the second post op days.

This study was performed in accordance with the Declaration of Helsinki and it was approved by the Institutional Review Board at the Poliambulatorio del Secondo Parere (Modena, Italy) were the study was performed.

\section{Statistical analysis}

Data were analyzed using GraphPad Prism 6 software (GraphPad Software, Inc., La Jolla, CA, USA). All data are presented as the means \pm standard error of the mean and were first checked for normality using the D'Agostino-Pearson normality test. A paired Student's $t$-test was used to compare changes in values after 2 weeks treatment versus baseline. Difference in values between the two groups was analyzed using a two-way analysis of variance (ANOVA) followed by Sidak's multiple comparisons test.

\section{Abbreviations}

SLO: Shark liver oil; AKG: Alkylglycerols; NK: Natural killer; IL-12: Interleukine12; IFN- $\gamma$ : Interferon-gamma; WBC: White blood cells; IgM: Immunoglobulin 
M; IgA: Immunoglobulin A; CRP: Reactive C protein; ESR: Erythrocyte sedimentation rate.

\section{Competing interests}

The authors declare that they have no competing interests.

\section{Authors' contributions}

ADC and BP have made substantial contributions to conception and design, or acquisition of data, or analysis and interpretation of data; have been involved in drafting the manuscript or revising it critically for important intellectual content. AP was involved in the analysis and interpretation of data. BP has given final approval of the version to be published and agreed to be accountable for all aspects of the work in ensuring that questions related to the accuracy or integrity of any part of the work are appropriately investigated and resolved. All authors read and approved the final manuscript.

\section{Acknowledgements}

The authors contributed equally to this work. This review was not supported by grants.

\footnotetext{
Author details

${ }^{1}$ Azienda Ospedaliero-Universitaria Policlinico di Modena, Surgery and Surgical Specialties department, University of Modena and Reggio Emilia, via del Pozzo 71, Modena 41124, Italy. ${ }^{2}$ Department of Biomedical Sciences, Faculty of Medicine G. d'Annunzio University, Chieti-Pescara, Italy. ${ }^{3}$ Poliambulatorio del Secondo Parere, viale Reiter 14, Modena 41125, Italy. ${ }^{4}$ Scuola di Specializzazione in Biochimica Clinica, G. d'Annunzio University, Chieti-Pescara, Italy.
}

Received: 1 September 2014 Accepted: 8 October 2014 Published: 27 November 2014

\section{References}

1. Iannitti T, Palmieri B: An update on the therapeutic role of alkylglycerols. Mar Drugs 2010, 8:2267-2300.

2. Molina S, Moran-Valero Ml, Martin D, Vazquez L, Vargas T, Torres CF, Ramirez De Molina A, Reglero G: Antiproliferative effect of alkylglycerols as vehicles of butyric acid on colon cancer cells. Chem Phys Lipids 2013, 175-176:50-56.

3. Bartfai E, Orsiere T, Duffaud F, Villani P, Pompili J, Botta A: [Studies on the genotoxic effects of crude liver oils from 3 species of Mediterranean sharks by means of in vitro micronucleus test using human lymphocytes]. Ann Biol Clin 2000, 58:595-600.

4. lagher F, De Brito Belo SR, Souza WM, Nunes JR, Naliwaiko K, Sassaki GL, Bonatto SJ, De Oliveira HH, Brito GA, De Lima C, Kryczyk M, de Souza CF, Steffani JA, Nunes EA, Fernandes LC: Antitumor and anti-cachectic effects of shark liver oil and fish oil: comparison between independent or associative chronic supplementation in Walker 256 tumor-bearing rats. Lipids Health Dis 2013, 12:146.

5. Nowicki R, Baranska-Rybak W: [Shark liver oil as a supporting therapy in atopic dermatitis]. Pol Merkur Lekarski 2007, 22:312-313.

6. Tsujimoto M, Toyama Y: Ueber die unverseifbaren Bestandteile (hoheren Alkohole) der Haifishund Rochen-leberole. Chemische Umschau auf dem Gebiet der Fette, Oele, Wachse und Harze 1922, 29:43-45.

7. Werbach MR: Alkylglycerols and Cancer. J Orthomol Med 1994, 9:95-102.

8. Ngwenya BZ, Foster DM: Enhancement of antibody production by lysophosphatidylcholine and alkylglycerol. Proc Soc Exp Biol Med Soc Exp Biol Med 1991, 196:69-75.

9. Brohult A, Brohlt J, Brohult S: Effect of irradiation and alkoxyglycerol treatment on the formation of antibodies after salmonella vaccination. Experientia 1972, 28:954-955.

10. Debouzy J-C, Crouzier D, Lefebvre B, Dabouis V: Study of alkylglycerol containing shark liver oil: a physic chemical support for biological effects. Drug Target Insights 2008, 3:125-135.

11. Hichami A, Duroudier V, Leblais V, Vernhet L, Le Goffic F, Ninio E, Legrand A: Modulation of platelet-activating-factor production by incorporation of naturally occurring 1-O-alkylglycerols in phospholipids of human leukemic monocyte-like THP-1 cells. Eur J Biochem 1997, 250:242-248.

12. Marigny K, Pedrono F, Martin-Chouly CA, Youmine H, Saiag B, Legrand AB: Modulation of endothelial permeability by 1-O-alkylglycerols. Acta Physiol Scand 2002, 176:263-268.
13. Pedrono F, Cheminade C, Legrand AB: Natural 1-O-alkylglycerols reduce platelet-activating factor-induced release of $[3 \mathrm{H}]$-serotonin in rabbit platelets. Prostaglandins Leukot Essent Fatty Acids 2004, 71:19-23.

14. Pedrono F, Martin B, Leduc C, Le Lan J, Saiag B, Legrand P, Moulinoux JP, Legrand $A B$ : Natural alkylglycerols restrain growth and metastasis of grafted tumors in mice. Nutr Cancer 2004, 48:64-69.

15. Skopinska-Rozewska E, Krotkiewski M, Sommer E, Rogala E, Filewska M, Bialas-Chromiec B, Pastewka K, Skurzak H: Inhibitory effect of shark liver oil on cutaneous angiogenesis induced in Balb/c mice by syngeneic sarcoma L-1, human urinary bladder and human kidney tumour cells. Oncol Rep 1999, 6:1341-1344.

16. Simard B, Bouamrani A, Jourdes P, Pernod G, Dimitriadou V, Berger F: Induction of the fibrinolytic system by cartilage extract mediates its antiangiogenic effect in mouse glioma. Microvasc Res 2011, 82:6-17.

17. Solly F, Fish R, Simard B, Bolle N, Kruithof E, Polack B, Pernod G: Tissue-type plasminogen activator has antiangiogenic properties without effect on tumor growth in a rat C6 glioma model. Cancer Gene Ther 2008, 15:685-692.

18. Hartvigsen K, Ravandi A, Harkewicz R, Kamido H, Bukhave K, Holmera G, Kuksis A: 1 -O-alkyl-2-(omega-oxo)acyl-sn-glycerols from shark oil and human milk fat are potential precursors of PAF mimics and GHB. Lipids 2006, 41:679-693.

19. Yamamoto N, St Claire DA Jr, Homma S, Ngwenya BZ: Activation of mouse macrophages by alkylglycerols, inflammation products of cancerous tissues. Cancer Res 1988, 48:6044-6049.

20. Deniau AL, Mosset $P$, Le Bot $D$, Legrand AB: Which alkylglycerols from shark liver oil have anti-tumour activities? Biochimie 2011, 93:1-3.

doi:10.1186/1476-511X-13-178

Cite this article as: Palmieri et al.: Jurassic surgery and immunity enhancement by alkyglycerols of shark liver oil. Lipids in Health and Disease 2014 13:178.

\section{Submit your next manuscript to BioMed Central and take full advantage of:}

- Convenient online submission

- Thorough peer review

- No space constraints or color figure charges

- Immediate publication on acceptance

- Inclusion in PubMed, CAS, Scopus and Google Scholar

- Research which is freely available for redistribution

Submit your manuscript at www.biomedcentral.com/submit 